\title{
Growth arrest-specific gene 6 protein promotes the proliferation and migration of endothelial progenitor cells through the PI3K/AKT signaling pathway
}

\author{
PEI-YUAN ZUO, XING-LIN CHEN, YING-HONG LEI, CHENG-YUN LIU and YU-WEI LIU \\ Department of Geriatrics, Union Hospital, Tongji Medical College, \\ Huazhong University of Science and Technology, Wuhan, Hubei 430022, P.R. China
}

Received December 12, 2013; Accepted April 7, 2014

DOI: $10.3892 / \mathrm{ijmm} .2014 .1754$

\begin{abstract}
Endothelial progenitor cells (EPCs) play an important role in endothelial repair and vascular regeneration. Growth arrest-specific gene 6 (Gas6) is a novel key regulator of the vascular system, which is linked to a number of cardiovascular diseases. However, the effects of Gas6 on EPCs have not been elucidated to date. The present study was designed to determine the biological function of EPCs treated with Gas6 and to eludicate the underlying mechanisms. EPCs were isolated from umbilical cord blood and treated with various concentrations $(25,50,100$ and $200 \mathrm{ng} / \mathrm{ml})$ of Gas6. The proliferation, migration and angiogenesis of the Gas6-treated EPCs were evaluated by MTT assay, Transwell assay and in vitro tube formation assay, respectively. The phosphorylation status of AKT and ERK was evaluated by western blot analysis. The results demonstrated that treatment with Gas6 enhanced the proliferation and migration of the EPCs in a dose-dependent manner. However, Gas6 did not promote the differentiation of EPCs on Matrigel. Gas6 induced the phosphorylation of AKT, but not that of ERK. The enhanced proliferation and migration induced by Gas6 was markedly suppressed by the inhibitor of PI3K but not by that of ERK. These results suggest that Gas6 activates the AKT signaling pathway, which, in turn, promotes the proliferation and migration of EPCs.
\end{abstract}

\section{Introduction}

The enhancement of re-endothelialization is a critical therapeutic option to repair injured blood vessels. Regeneration of the injured endothelium is linked to the proliferation and migration of neighboring endothelial cells (ECs) (1). Mature ECs are

Correspondence to: Professor Cheng-Yun Liu, Department of Geriatrics, Union Hospital, Tongji Medical College, Huazhong University of Science and Technology, 1277 Jiefang Avenue, Wuhan, Hubei 430022, P.R. China

E-mail: lcyun@medmail.com.cn

Key words: growth arrest-specific gene 6, endothelial progenitor cells, proliferation, migration, $\mathrm{PI} 3 \mathrm{~K} / \mathrm{AKT}$ pathway a group of cells with low proliferative potential and a limited capacity to substitute the damaged endothelium. Accumulating evidence has indicated that endothelial progenitor cells (EPCs), which can home to sites of tissue injury and differentiate into mature ECs and participate in re-endothelialization after vascular injury, may be an endogenous repair mechanism to maintain the integrity of the endothelial monolayer by replacing denuded areas of the artery (2-4). The discovery of new methods to improve the EPC re-endothelialization process is currently the subject of intensive investigation.

Growth arrest-specific gene 6 (Gas6), is a member of the vitamin K-dependent family of proteins, which includes the procoagulant factors II, VII, IX, and X, and the anticoagulant factors, protein $\mathrm{C}$ and $\mathrm{S}$, as well as protein $\mathrm{Z}$ (5). Even though Gas6 was discovered as a homolog of protein $S$ more than a decade ago, it plays no role in the generation of fibrin (6). Instead, Gas6 exerts several other functions that belong to the repertoire of growth or survival factors. Firstly, the original observation that Gas6 is upregulated in growth-arrested cells suggests a role in the protection from certain cellular stresses, such as apoptosis (7). Subsequently, a number of studies have demonstrated the ability of Gas6 to promote either cell survival (8) and/or proliferation (9). Additional growth factorlike properties of Gas 6 have been reported, including the stimulation of cell migration and cell-cell adhesion (10).

The first hint that Gas6 may be important in the vasculature came from the purification of Gas6 from the conditioned medium of vascular smooth muscle cells (VSMCs) that potentiated the growth response of VSMCs treated with angiotensin II (11). It was subsequently discovered that the expression of Gas6 was increased in the injured rat carotid, with a time course paralleling that of neointima formation (12). Further experimental evidence indicated that ECs in culture express and release Gas6, and that it promotes cell survival, possibly through an autocrine pathway (13-16). These findings highlight the importance of Gas6 in vascular function. Gas6 was found to bind to the extracellular regions of three distinct receptor tyrosine kinases, namely Axl, Mertk and Tyro3. A recent study demonstrated that Axl may be a potential angiogenic target (17). Considering that Gas6 has various potential bioactivities, it is of great interest to identify those that have a significant impact on EPCs. 


\section{Materials and methods}

Isolation and culture of late EPCs. Ethical approval was granted by the Institutional Review Board of Tongji Medical College, Hubei, China. Informed consent was obtained from healthy donors prior to the collection of umbilical cord blood. The mononuclear cells were isolated from umbilical cord blood by Ficoll density gradient centrifugation with Histopaque 1077 (Sigma, St. Louis, MO, USA). The isolated cells were resuspended using an EGM-2 BulletKit system (catalog number CC-3202; Lonza) consisting of endothelial basal medium, $5 \%$ fetal bovine serum, human epidermal growth factor (hEGF), vascular endothelial growth factor (VEGF), human fibroblast growth factor (hFGF), hFGF-B, insulin-like growth factor (IGF)-1 and ascorbic acid. Mononuclear cells were seeded on fibronectin-coated (Sigma) dishes and maintained in a $5 \% \mathrm{CO}_{2}$ incubator at $37^{\circ} \mathrm{C}$. Three days after planting, the non-adherent cells were removed and, thereafter, the medium was changed every 2 days. Cobblestonelike cell colonies were observed after 2 weeks.

Characterization of EPCs. Direct fluorescent staining was used to detect the dual binding of 1, 1-dioctadecyl-3, 3, 3, 3-tetramethylindocarbocyanine-labeled acetylated low-density lipoprotein (Dil-ac-LDL; molecular probe) and fluorescein isothiocyanate (FITC)-conjugated Ulex europaeus agglutinin lectin (UEA-1; Sigma). The cells were incubated with $2.4 \mu \mathrm{g} / \mathrm{ml}$ Dil-ac-LDL for $4 \mathrm{~h}$ in a cell incubator. The cells were then washed and fixed with $4 \%$ paraformaldehyde for $10 \mathrm{~min}$ and incubated with $10 \mu \mathrm{g} / \mathrm{ml}$ FITC-labeled UEA-1 for $1 \mathrm{~h}$. Subsequently, the cells were washed and incubated with Hoechst 33258. Double-positive cells were observed under a laser confocal microscope (FV500; Olympus, Tokyo, Japan). To assess the expression of surface antigen on the cells, we performed fluorescence-activated cell sorter (FACS) analysis. Five million EPCs per sample were stained for $30 \mathrm{~min}$ at $4^{\circ} \mathrm{C}$ with fluorescein isothiocyanate-conjugated monoclonal mouse anti-human CD34 (BD Pharmingen, San Diego, CA, USA) antibody, phycoerythin-conjugated monoclonal mouse anti-human VEGFR2 (BD Pharmingen) antibody and mouse anti-human CD133 antibody conjugated to allophyocyanin (Miltenyi Biotec, Auburn, CA, USA). Data were processed using FlowJo software (version 7.6) .

Proliferation assay. The effects of Gas6 on EPC proliferation were determined by MTT assay. A total of $5 \times 10^{3}$ cells/well were seeded on 96-well culture plates and then deprived of serum for $12 \mathrm{~h}$ to achieve cell cycle synchronization. The dose range $(25,50,100$ and $200 \mathrm{ng} / \mathrm{ml}$ ) of Gas6 (R\&D Systems, Minneapolis, MN, USA) was the same as that used in previous studies $(18,19)$. The control groups received a dilution of water equivalent to Gas6 at the highest concentration. The cells were cultured and treated for 24 and $48 \mathrm{~h}$, respectively. MTT solution $(5 \mathrm{mg} / \mathrm{ml})$ was added to each well. Following $4 \mathrm{~h}$ of incubation at $37^{\circ} \mathrm{C}$, the supernatant was discarded and the EPC preparation was shaken with dimethyl sulfoxide (DMSO) for $10 \mathrm{~min}$ before the optical density measurement $(490 \mathrm{~nm})$ was taken. The results were calculated from 4 experiments with 5 replicates of each. To investigate the effects of PI3K and ERK inhibitors on the viability of EPCs, the cells were pre-treated in the absence or presence of LY294002 (10, 20 and $30 \mu \mathrm{mol} / \mathrm{l})$
(Cell Signaling Technology, Inc., Danvers or Beverly, MA, USA) or PD98059 $(5,10$ and $20 \mu \mathrm{mol} / \mathrm{l}$ ) (Cell Signaling Technology, Inc.) for $30 \mathrm{~min}$. After being cultured for $48 \mathrm{~h}$, the EPCs were supplemented with MTT $(5 \mathrm{mg} / \mathrm{ml})$ and incubated for another $4 \mathrm{~h}$. The EPC preparation was then shaken with DMSO for $10 \mathrm{~min}$, before the OD measurement at $490 \mathrm{~nm}$ was taken.

Migration assay. The migration ability of the EPCs was evaluated using a Transwell migration assay (Costar, Cambridge, MA, USA) with 6.5 -mm-diameter polycarbonate filters $(8 \mu \mathrm{m}$ pore size). Gas6 with various concentrations plus endothelial basal medium-2 and $0.2 \%$ FBS were placed in the lower wells. EPCs $\left(4 \times 10^{4}\right.$ cells/well) were seeded onto the upper chamber supplemented with serum-free endothelial growth medium. After $12 \mathrm{~h}$ of incubation in the cell incubator, the upper chamber was removed and wiped clean with a cotton swab; the lower side of the filter was washed with PBS and fixed with $4 \%$ paraformaldehyde for $10 \mathrm{~min}$. For quantification, the cell nucleus was stained with crystal violet. Cell migration into the lower chamber and attachment to the lower side of the filter were manually counted in 16 fixed microscopic fields (magnification, $\mathrm{x} 400$ ) by independent investigators blinded to the treatment regimen, randomly. Each test was performed in triplicate, and assays were repeated 3 times with individual EPCs. When investigating the effects of PI3K and ERK inhibitors on the migration ability of the cells, the EPCs were cultured in the absence or presence of $200 \mathrm{ng} / \mathrm{ml}$ Gas6 and the indicated concentrations of $20 \mu \mathrm{mol} / 1 \mathrm{LY} 294002$ or $5 \mu \mathrm{mol} / 1$ PD 98059 for $24 \mathrm{~h}$. The following steps were the same as those described above.

In vitro tube-formation assay. In vitro tube-formation assay was performed using Matrigel (BD Biosciences, San Jose, CA, USA) according to the manufacturer's instructions. Passage-3 EPCs were incubated with an additional 50, 100 and $200 \mathrm{ng} /$ $\mathrm{ml} \mathrm{Gas} 6$ and $10 \mathrm{ng} / \mathrm{ml}$ VEGF or $200 \mathrm{ng} / \mathrm{ml}$ Gas 6 plus $10 \mathrm{ng} / \mathrm{ml}$ VEGF for $24 \mathrm{~h}$. The Matrigel solution was thawed at $4^{\circ} \mathrm{C}$ for 30 min to allow gelation, then $1 \times 10^{4}$ EPCs with the previous treatment were placed on top of the Matrigel. After $12 \mathrm{~h}$ of incubation, the mean tube length was calculated in 3 randomly selected fields from each well (x100) using Image-Pro Plus software and was calculated against the value of the control groups. The experiment was repeated 5 times.

Western blot analysis. The EPCs pre-treated with $200 \mathrm{ng} / \mathrm{ml}$ Gas6 were lysed with RIPA buffer and electrophoresed on $10 \%$ SDS-PAGE gels at $100 \mathrm{~V}$ for $2 \mathrm{~h}$, and electroblotted onto a PVDF membrane at $275 \mathrm{~mA}$ for $12 \mathrm{~h}$. The membrane was incubated with 5\% fat-free milk PBS for $2 \mathrm{~h}$ at room temperature. The membrane was then incubated with anti-AKT, anti-ERK (1:500; Cell Signaling Technology, Inc.), anti-phospho-AKT and anti-phospho-ERK (1:500; Cell Signaling Technology,Inc.) rabbit monoclonal antibodies followed by the addition of a goat anti-rabbit peroxidase-conjugated secondary antibody (Santa Cruz Biotechnology, Inc., Santa Cruz, CA, USA). The immunoreactive bands were then visualized with a chemiluminescence reagent (Thermo Fisher Scientific Inc., Rockford, IL, USA) and exposed to X-ray film. The density of each band was quantified using ImageJ software. All the assays were performed in triplicate with individual EPCs. 


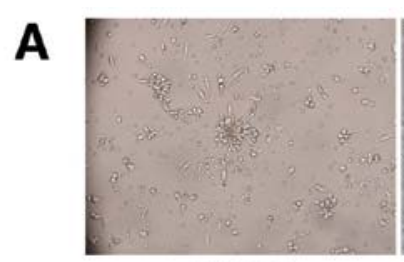

Day 7

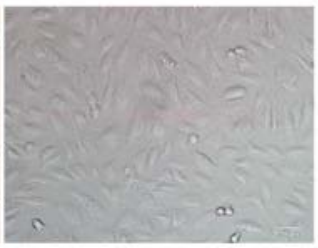

Day 21

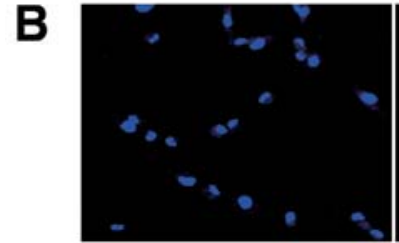

HOECHST

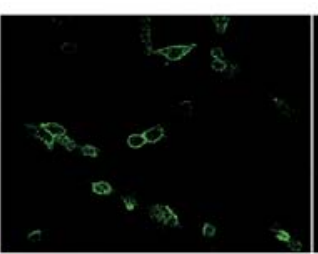

UEA-1

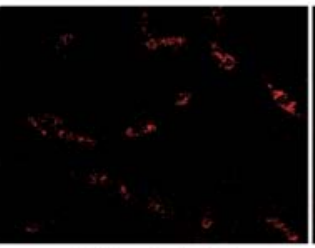

Dil-ac-LDL

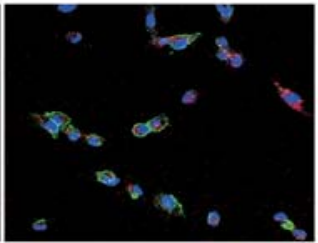

Merged

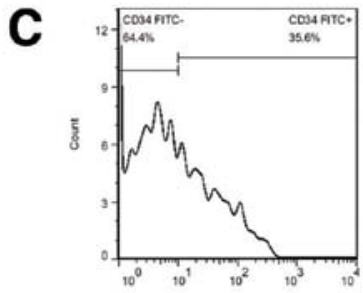

CD34 FITC: $35.6 \%$

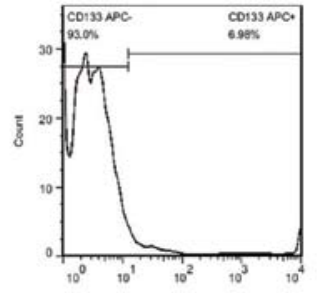

CD133 APC: $6.98 \%$

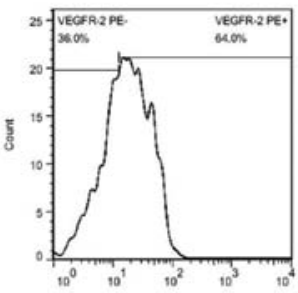

VEGFR2 PE: $64 \%$

Figure 1. Morphology and characterization of cultured endothelial progenitor cells (EPCs). (A) Three days after culturing. Non-adherent cells were removed and adherent EPCs exhibited a spindle-shaped morphology (day 7; magnification, x100). Late EPCs with cobblestone-like morphology were grown to confluence after 2 weeks (day 21; magnification, x200). (B) Fluorescent staining showed that the cells were positive for Ulex europaeus agglutinin (UEA)-1 and 1,1'-dioctadecyl-1-3,3,3',3'-tetramethyl-indo-carbocyanine (DiI) (magnification, x400). (C) Flow cytometric analysis of cell surface markers expression EPCs at 14 days of culture in vitro. Cells were positive for the hematopoietic stem cell markers, CD133 (6.98 $\pm 0.96 \%)$, CD34 (35.6 $\pm 2.25 \%)$ and CD133 (64.0 $\pm 4.10 \%)$. Data are the means \pm SD percentage of positive cells from 3 samples.

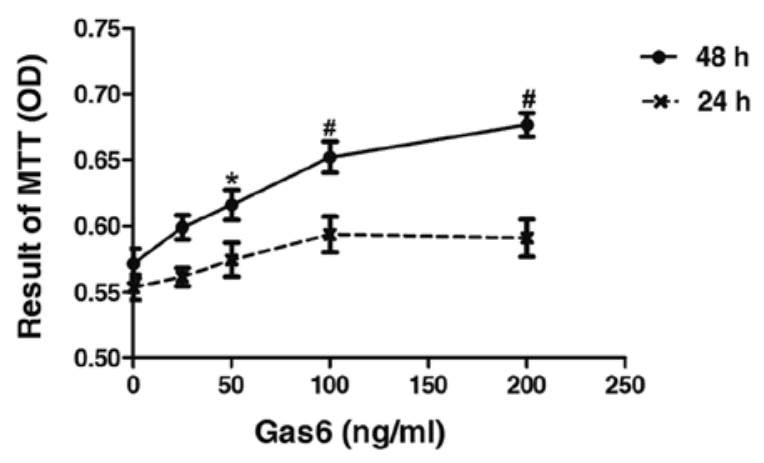

Figure 2. Effect of growth arrest-specific gene 6 (Gas6) on endothelial progenitor cell (EPC) proliferation. Gas6 upregulated EPCs in dose- and time-dependent manner. Following incubation with 50, 100 and $200 \mathrm{ng} / \mathrm{ml}$ Gas6 for $48 \mathrm{~h}$, the number of EPCs was significantly upregulated compared with the controls. Treatment with increasing concentrations of Gas 6 for $24 \mathrm{~h}$ did not affect the proliferation ability of EPCs compared with the controls. Data are expressed as the means \pm SD averaged from at least 3 independent experiments $\left({ }^{*} \mathrm{P}<0.05,{ }^{\#} \mathrm{P}<0.01\right.$ compared with the control, $\mathrm{n} \geq 3$ ).

Statistical analysis. Results were obtained from at least 3 independent experiments and data are presented as the means \pm SD. The Student's t-test was performed for statistical comparisons between 2 groups and ANOVA was used for comparisons between $>2$ groups. A P-value $<0.05$ was considered to indicate a statistically significant difference.

\section{Results}

Characterization of EPCs. Late EPCs appeared after 1-2 weeks as small colonies in cultures of mononuclear cells (MNCs) and developed a cobblestone-like cell morphology over time (Fig. 1A). To confirm the EPC phenotype, attached mononuclear cells were incubated with Dil-ac-LDL and FITC-UEA-1. Cells demonstrating double-positive fluorescence were identified as differentiated EPCs. Almost all adherent cells were shown to endocytose Dil-ac-LDL and bind FITC-UEA-1 (Fig. 1B). Flow cytometric analysis for positive staining with CD34, VEGFR2 and CD133 further confirmed the EPC characteristics (Fig. 1C).

Gas6 stimulates the proliferation of human EPCs. To determine the effects of Gas6 on the growth of human EPCs, we performed a time- and dose-response experiment. Gas6 at concentrations of 50, 100 and $200 \mathrm{ng} / \mathrm{ml}$ induced an increase in the proliferation of EPCs of $7.26 \%$ ( $\mathrm{P}<0.05$ vs. control), $14.10 \%(\mathrm{P}<0.001$ vs. control) and $18.40 \%$ ( $\mathrm{P}<0.001$ vs. control), respectively, after $48 \mathrm{~h}$ of culture (Fig. 2). However, treatment with increased concentrations of Gas 6 for $24 \mathrm{~h}$ did not affect the proliferative ability of the EPCs compared with the control. The effects on cell proliferation induced by Gas6 occurred in a dose- and time-dependent manner.

Gas6 stimulates EPC migration. The effects of Gas6 on late EPC migration were determined by a Transwell assay (Fig. 3). 
A

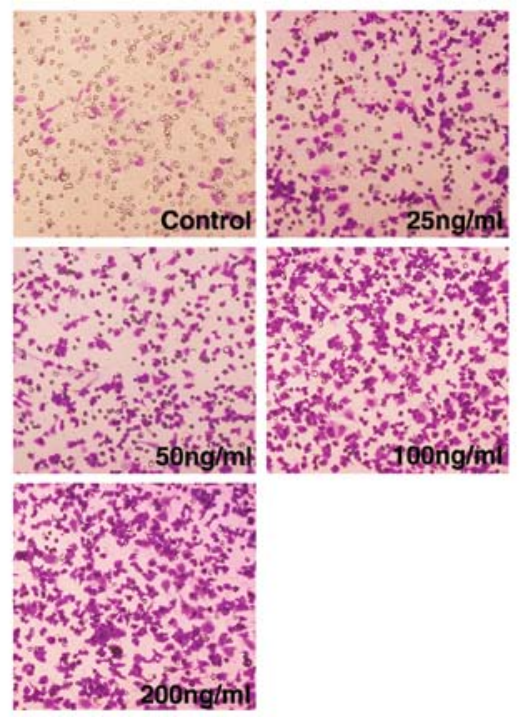

B

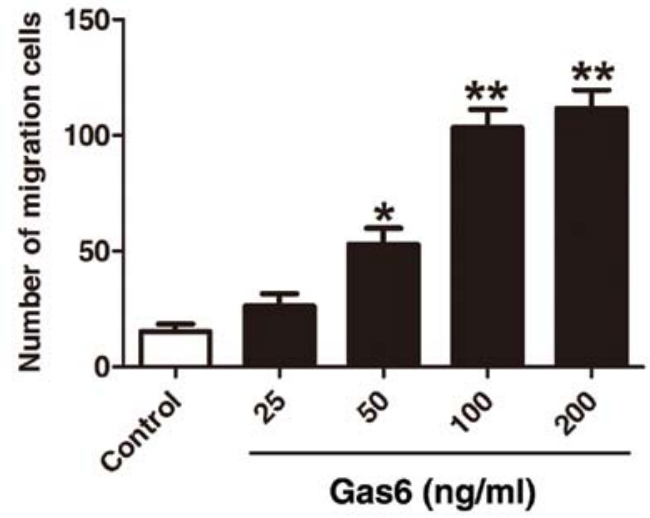

Figure 3. Effect of growth arrest-specific gene 6 (Gas6) on endothelial progenitor cell (EPC) migration. Gas6 increased EPC migration in a concentration-dependent manner. A large number of cells migrated to the lower side of the membrane in the Transwell chamber after being stimulated with Gas6 (magnification, $\mathrm{x} 200$ ). (A) The cells with purple staining represent migrated cells stained by crystal violet. Fields were randomly selected from various section levels to ensure objective sampling. (B) Columns represent the number of migrated cells. Data are shown as the means \pm SD from 3 independent experiments $\left({ }^{*} \mathrm{P}<0.05,{ }^{* *} \mathrm{P}<0.01\right.$ vs. control, $n=3$ ).
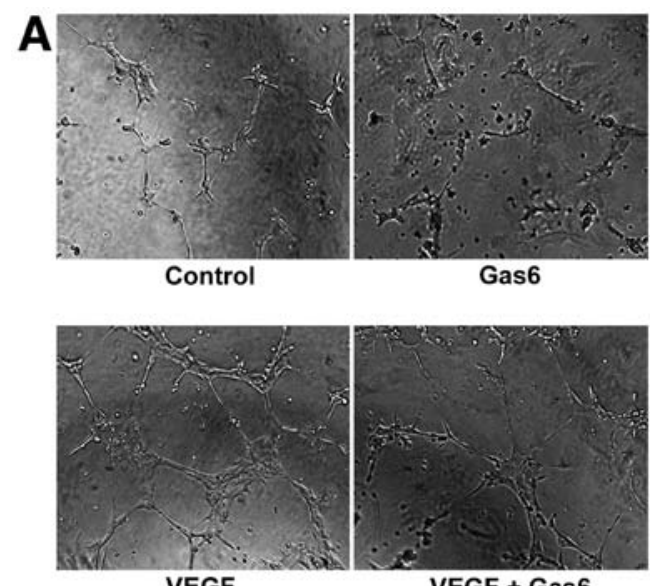

VEGF

VEGF + Gas6

B

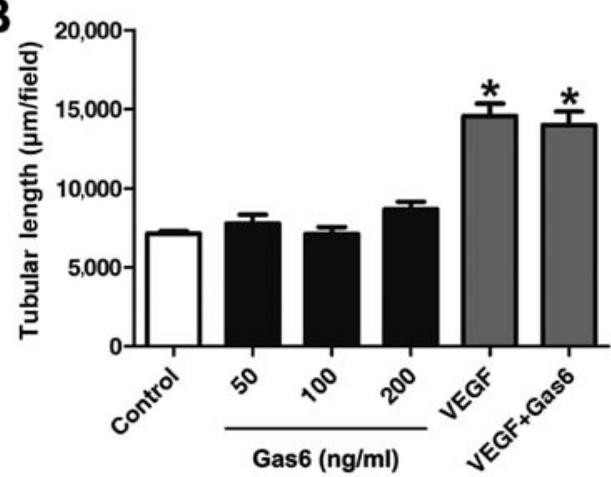

Figure 4. Effect of growth arrest-specific gene 6 (Gas6) on tube formation of endothelial progenitor cells (EPCs) on Matrigel. (A) Photomicrographs (magnification, x100) of network formed by EPCs $12 \mathrm{~h}$ following no treatment or pre-treatment with $200 \mathrm{ng} / \mathrm{ml}$ Gas6, VEGF-A or VEGF-A plus $200 \mathrm{ng} / \mathrm{ml} \mathrm{Gas6}$ (B) Quantification of total tubular length. Gas6 at 50, 100 (data not shown) and $200 \mathrm{ng} / \mathrm{ml}$ did not ameliorate the capacity of capillary-like structures forming compared with control. Gas6 did not alter VEGF-A-dependent tube formation. Data represent the average total capillary vessel length per image obtained $\pm \mathrm{SD}\left(\mathrm{n} \geq 3,{ }^{*} \mathrm{P}<0.01\right.$ vs. control group).
A large number of cells treated with Gas6 had migrated to the lower side of the membrane in the Transwell chamber. Treatment with Gas6 increased EPC migration in a dose-dependent manner (control, $15.33 \pm 5.50 ; 25 \mathrm{ng} / \mathrm{ml}, 36.00 \pm 6.55 ; 50 \mathrm{ng} /$ $\mathrm{ml}, 53.00 \pm 12.00 ; 100 \mathrm{ng} / \mathrm{ml}, 103.33 \pm 13.57$; and $200 \mathrm{ng} / \mathrm{ml}$, $111.66 \pm 13.57$ cells, respectively), with a significant effect at a dose of $50 \mathrm{ng} / \mathrm{ml}(\mathrm{P}<0.05$ vs. control); the most significant effect was observed with the highest Gas6 dose used (200 ng/ $\mathrm{ml} ; \mathrm{P}<0.01$ vs. control). However, there was no statistically significant difference between the 100 and $200 \mathrm{ng} / \mathrm{ml}$ groups $(\mathrm{P}=0.384)$.

Gas6 does not promote EPC differentiation on Matrigel. Gas6 promoted the proliferation and migration of EPCs; we thus investigated whether this protein affects the capillary-like structure formation of EPCs. Following stimulation for $12 \mathrm{~h}$, Gas6 at 50, 100 and $200 \mathrm{ng} / \mathrm{ml}$ did not ameliorate the capacity of the cells to form capillary-like structures compared with the control. VEGF-A is recognized as a key regulator of tube formation in the process of angiogenesis (35). Further investigation indicated that Gas6 did not alter VEGF-A-dependent tube formation (Fig. 4).

Effects of Gas6 on the phosphorylation of AKT. To elucidate the molecular mechanisms underlying the effects of Gas6 on EPCs, the phosphorylation status of the MAP kinases and AKT, which are implicated in EPC proliferation and function, was examined by western blot analysis $(20,21)$. As shown in Fig. 5B, AKT phosphorylation in the EPCs was markedly induced at $5 \mathrm{~min}$ and persisted for up to the 30-min time point following treatment with Gas6. However, as demonstrated in Fig. 5A, Gas6 did not cause any significant change in the phopho-ERK/ERK level over 1-h period, indicating that Gas6 had no effect on ERK activation. To confirm that Gas6 promotes EPC viability and motility through the AKT path- 
A

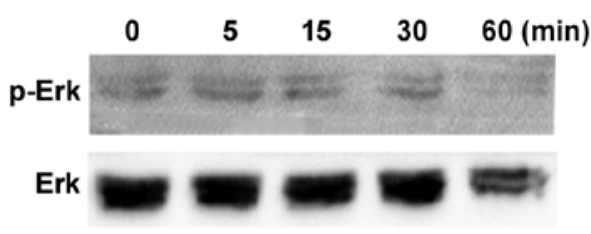

B

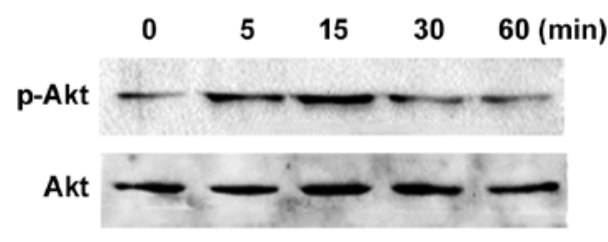

C

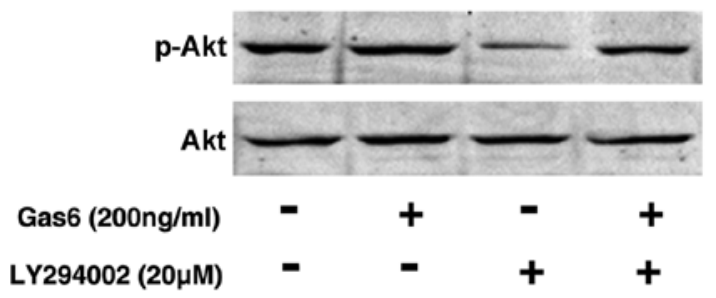

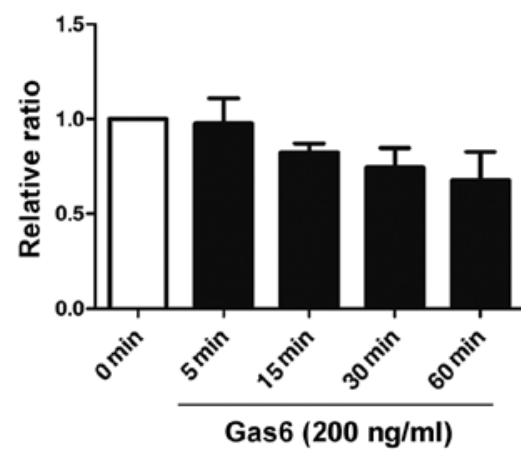
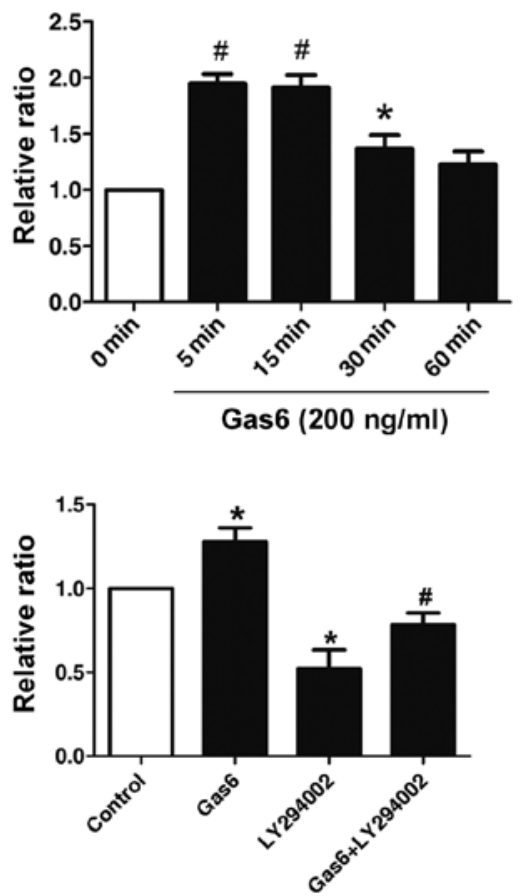

Figure 5. Growth arrest-specific gene 6 (Gas6) phosphorylation of AKT, but not ERK. (A) Gas6 had no effect on ERK activation. (B) The phosphorylation of AKT was increased in a time-dependent manner $\left[{ }^{\#} \mathrm{P}<0.01\right.$ vs. dimethyl sulfoxide (DMSO)-treated control cells; ${ }^{*} \mathrm{P}<0.05$ vs. DMSO-treated control cells]. (C) LY294002 inhibited the phosphorylation of AKT; used in combination with Gas6, Gas6 partly reversed the inhibition of p-AKT with LY294002 ( $\mathrm{P}<0.05$ vs. DMSO-treated control cells; ${ }^{\#} \mathrm{P}<0.05$ vs. the Gas6 group). Blots are representative of at least 3 separate experiments. Densitometric analysis shows the relative ratios of phosphorylated AKT/total AKT and phosphorylated ERK/total ERK, and the ratio for the control is arbitrarily presented as 1 . Columns indicate means of 3 independent experiments, and bars represent the means \pm SD of 3 separate experiments.

ways, we treated the EPCs with LY294002 (PI3K inhibitor) alone or in combination with Gas6. LY294002 inhibited the phosphorylation of AKT; when used in combination with Gas6, Gas6 partly reversed the inhibition of phospho-AKT induced by LY294002 (Fig. 5C). These results indicate that Gas6 promotes EPC proliferation and migration, most likely through the AKT signaling pathway.

Effects of PI3K or ERK inhibitor on Gas6-induced EPC proliferation. To further confirm the roles of AKT in the Gas6-induced effects on EPCs, we determined the effects of AKT inhibition on EPC proliferation. As shown in Fig. 6, the PI3K inhibitor, LY294002, at dose $20 \mu \mathrm{mol} / 1$ did not alter the viability of the control EPCs, but markedly attenuated the effects of Gas6 on EPC proliferation. However, PD98059, an ERK inhibitor, at a concentration of $5 \mu \mathrm{mol} / 1$, exhibited a similar effect between the absence and presence of Gas6induced EPC proliferation vs. their own control. The decrease in EPC proliferation in both the Gas6 group and the control group treated with PD98059 was due to ERK inhibition. These results suggest that AKT, but not ERK, is involved in the Gas6-induced EPC proliferation.

Effects of PI3K or ERK inhibitor on Gas6-induced EPC migration. The possible roles of AKT in the Gas6-induced augmentation of the EPC migration were also assessed. The results revealed that the Gas6-induced increase in EPC migration was substantially attenuated by LY294002 (a PI3K inhibitor) (Fig. 7). By contrast, PD98059 (an ERK inhibitor) did not seem to have any significant effect on the migratory activity of these cells, suggesting that ERK is not involved in the stimulatory effects of Gas6 on EPC migration.

\section{Discussion}

To the best of our knowledge, the present study is the first to describe a novel effect by which Gas6 is engaged in the biological function of EPCs. The major findings of this study were 

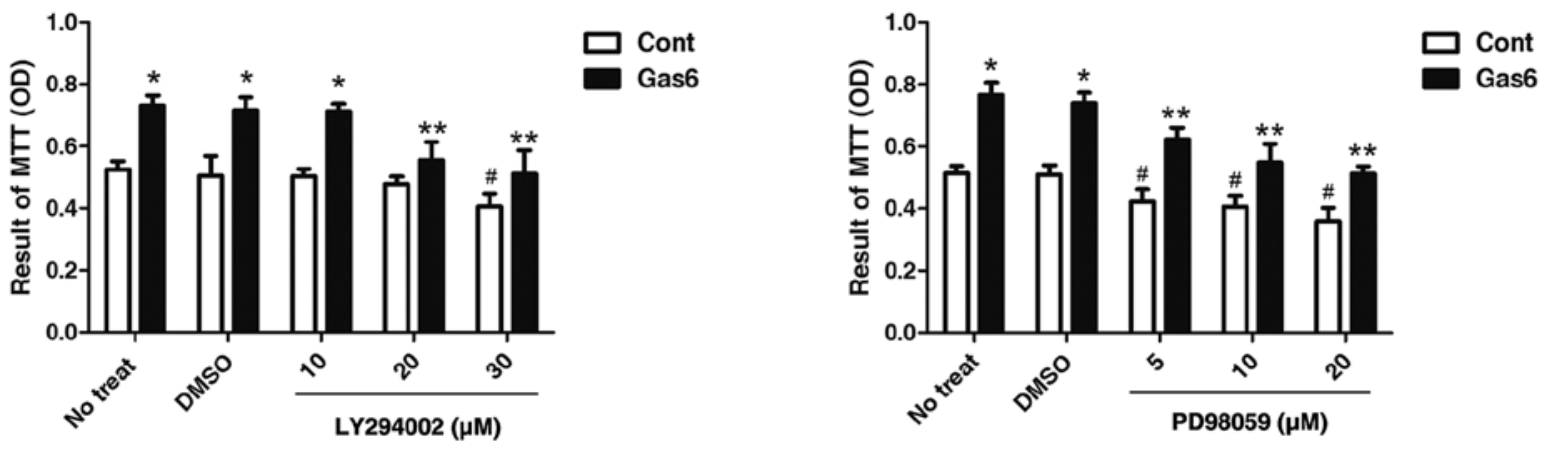

Figure 6. Effect of AKT or ERK inhibition on the growth arrest-specific gene 6 (Gas6)-induced endothelial progenitor cell (EPC) proliferation. EPCs were cultures in the absence or presence of $200 \mathrm{ng} / \mathrm{ml}$ Gas6 and the indicated concentrations of LY294002 or PD98059. Cell proliferation was then assessed by MTT assay ["P $<0.05$, Gas6 treated cells vs. cells without Gas6 treatment (controls); *" $\mathrm{P}<0.05$ vs. dimethyl sulfoxide (DMSO)-treated cells with Gas6 treatment; ${ }^{\#} \mathrm{P}<0.05$ vs. DMSO-treated cells without Gas6 treatment]. Cont, controls.

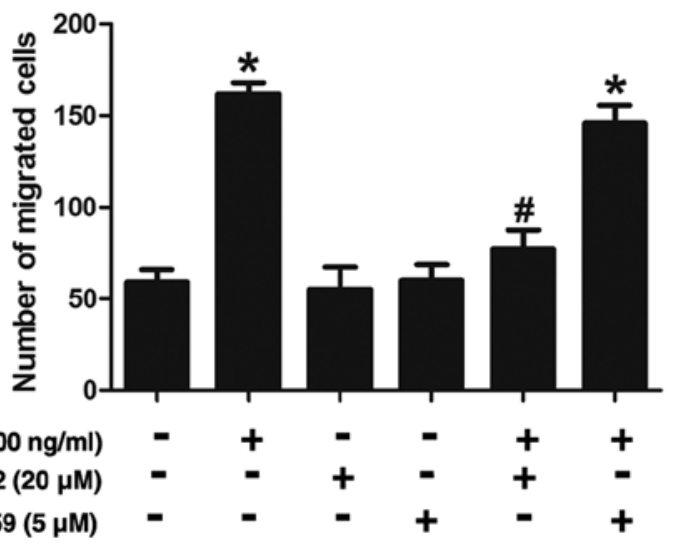

Figure 7. Effect of AKT or ERK inhibition on the growth arrest-specific gene 6 (Gas6)-induced endothelial progenitor cell (EPC) migration. EPCs were cultured in the absence or presence of $200 \mathrm{ng} / \mathrm{ml}$ Gas6 and $20 \mu \mathrm{mol} / 1$ LY294002 or $5 \mu \mathrm{mol} / 1$ PD98059. Cell migration was then assessed by Transwell assay ( $\mathrm{P}<0.01$ vs. control cells without Gas6 and kinase inhibitor treatment; ${ }^{\prime} \mathrm{P}<0.01$ vs. Gas6-treated cells).

the following: a) Gas6 significantly stimulated EPC proliferation and migration in vitro; b) Gas6 upregulated phospho-AKT but not phospho-ERK expression; c) Gas6 did not promote EPC differentiation on Matrigel; and d) the positive effects on proliferation and migration were abrogated in the presence of the PI3K-specific inhibitor, LY294002.

In recent years, it has become apparent that circulating EPCs are crucial to maintaining cardiovascular homeostasis and vascular integrity compared with mature ECs. It has been found that EPCs contribute up to $25 \%$ of ECs in newly formed vessels $(22,23)$. Cell therapy using EPCs in ischemic heart disease has been evaluated and proven to be safe and effective in a number of pre-clinical studies $(24,25)$. Accordingly, it is important to investigate the endogenous or exogenous factors that affect these cells. In the present study, we investigated whether the treatment of EPCs with Gas6 can improve the the proliferation, migration and tube formation of EPCs.

Gas6 is widely expressed and has been found in the lungs, heart, kidneys, intestine, ECs, bone marrow, VSMCs and monocytes and, at a very low level, in the liver. With the use of an ELISA-based method, Gas6 was detected in human plasma. It regulates homotypic and heterotypic adhesion (10), promotes proliferation $(26,27)$, survival $(15,28,29)$ and motility $(30,31)$ and amplifies the activity of extracellular stimuli $(11,32)$. In addition to the general effects of Gas6 mentioned above, we focused on its role in the cardiovascular system. Our previous study demonstrated that, in patients with acute coronary syndrome, Gas6 plasma levels at admission reflect the presence of common cardiovascular risk factors and can independently predict cardiovascular events (33). These data indicate that Gas6 may play an additional role in the vascular system. Therefore, on an experimental ground, we investigated the possible roles of Gas6 in the biological function of EPCs.

Firstly, we demonstrated the biological function of EPCs treated with Gas6. We concluded that Gas6 promotes EPC proliferation and migration. These results are in accordance with those of a previous study by Holland et al, who found that Gas6 silencing reduces EC haptotaxis towards vitronectin (34). Conversely, Gallicchio et al found that Gas6 stimulates Axl and inhibits the ligand-dependent activation of VEGF receptor 2 (VEGFR2) and the consequent activation of an angiogenic program in vascular ECs (35). In a recent study, Ruan et al found that Gas6 did not significantly alter the VEGF-Adependent activation of VEGFR-2 (17). It is very interesting that the two groups produced different results. We did not investigate VEGF-A-triggered signaling with Gas6; however, we found that Gas6 did not interfere with VEGF-A-induced tube formation in EPCs.

It has been previously demonstrated that Axl knockdown in ECs impaires tube formation (36). Further research has demonstrated that Axl regulates tube formation by the modulation of signaling through the angiopoietin/Tie 2 and Dickkopf pathways. In addition, Axl is essential for the VEGF-A-dependent activation of PI3K/AKT (17). Yet, we, as well as others have observed that Gas6 does not promote tube formation (35). Axl is an angiogenic receptor tyrosine kinase that can be engaged by multiple stimuli, including Gas6, VEGF, lactate or hypoxia (37). Thus, we consider that the angiogenic role of Axl may be independent of Gas6 administration. More complex mechanisms may be involved in the bioactivities of Gas6 in EPCs. Angiogenesis is a complex process, requiring the coordinated action of a variety of growth factors in ECs. A 
recent study demonstrated that, although Gas6 and Ang1 alone did not promote tube formation in ECs, the combination of Gas6 and Ang1 did (37). We thus consider the possibility that Gas6 alone may not promote tube formation, but it may do so when combined with other factors.

We extended our investigation with the aim of determining the mechanisms associated with the effects of Gas6 on EPCs. Previous studies have indicated that Gas6 plays an important role in some cell types through its regulation of the AKT and ERK signaling pathways following the initial effects on the cellular survival and proliferation $(9,38,39)$. Additionally, the AKT and ERK signaling pathways are well-documented signaling pathways involved in EPC biology $(40,41)$. To explore whether these same kinases play a role in the Gas6-induced proliferation and migration of EPCs, their phosphorylated status following Gas6 treatment was assessed. Our data demonstrated that Gas 6 induced the transient activation of AKT but not the ERK kinases.

To further demonstrate the role of AKT and ERK in the Gas6-induced proliferation and migration of EPCs, we performed additional experiments in which AKT and ERK activation was blocked by the pharmacological agents, LY294002 and PD98059, respectively. Our data demonstrated that at concentrations that did not affect the growth of the control EPCs, LY294002 markedly attenuated the cell proliferation and migration induced by Gas6. The decrease in EPC proliferation in both the GAS6 and control groups treated with PD98059 was due to ERK inhibition and not the blockade of GAS6-mediated ERK activation. Taken together, these findings, indicate that Gas6 promotes the EPC proliferation and migration through the PI3K/AKT pathway. It should be noted that the activation of PI3K/AKT is not sufficient to drive angiogenesis, while PI3K/AKT is required in regulating cell angiogenesis (41). The finding that Gas6 did not engage certain downstream signaling effectors, such as ERK, may account for the inability of Gas6 to promote angiogenic responses.

The Gas6-induced growth and differentiation of hematopoietic cells, particularly the erythroid progenitor cells, has been well documented $(42,43)$. The effects of Gas6 on EPCs have not been demonstrated, although EPCs and hematopoietic cells are derived from the same ancestor, i.e., the hemangioblast (44). It appears that Gas6 regulates EPC growth and differentiation through mechanisms that are distinct from those observed in erythroid progenitor cells. In conclusion, the present study demonstrates that Gas6 promotes EPC proliferation and migration through the PI3K/AKT signaling pathway. This poses an interesting question on the manipulation of EPCs with Gas6 to enhance the therapeutic effects of cell therapy in regenerating the endothelium. However, the results presented in this study are preliminary; therefore, further investigation is required in order for our data to be used as a basis for the development of a therapeutic strategy for re-endothelialization. Moreover, further stuides are required in order to explore the effects of Gas6 on animals.

\section{Acknowledgements}

This study was supported by a grant from the National Natural Science Foundation of China, no. 81370468.

\section{References}

1. Walter DH, Rittig K, Bahlmann FH, et al: Statin therapy accelerates reendothelialization: a novel effect involving mobilization and incorporation of bone marrow-derived endothelial progenitor cells. Circulation 105: 3017-3024, 2002.

2. He T, Smith LA, Harrington S, Nath KA, Caplice NM and Katusic ZS: Transplantation of circulating endothelial progenitor cells restores endothelial function of denuded rabbit carotid arteries. Stroke 35: 2378-2384, 2004.

3. Werner N, Junk S, Laufs U, et al: Intravenous transfusion of endothelial progenitor cells reduces neointima formation after vascular injury. Circ Res 93: e17-e24, 2003.

4. Li DW, Liu ZQ, Wei J, Liu Y and Hu LS: Contribution of endothelial progenitor cells to neovascularization (Review). Int J Mol Med 30: 1000-1006, 2012.

5. Hafizi S and Dahlback B: Gas6 and protein S. Vitamin K-dependent ligands for the Axl receptor tyrosine kinase subfamily. FEBS J 273: 5231-5244, 2006.

6. Stitt TN, Conn G, Gore M, et al: The anticoagulation factor protein S and its relative, Gas6, are ligands for the Tyro 3/Axl family of receptor tyrosine kinases. Cell 80: 661-670, 1995.

7. Schneider C, King RM and Philipson L: Genes specifically expressed at growth arrest of mammalian cells. Cell 54: 787-793, 1988.

8. Melaragno MG, Cavet ME, Yan C, et al: Gas6 inhibits apoptosis in vascular smooth muscle: role of Axl kinase and Akt. J Mol Cell Cardiol 37: 881-887, 2004.

9. Stenhoff J, Dahlback B and Hafizi S: Vitamin K-dependent Gas6 activates ERK kinase and stimulates growth of cardiac fibroblasts. Biochem Biophys Res Commun 319: 871-878, 2004.

10. McCloskey P, Fridell YW, Attar E, et al: GAS6 mediates adhesion of cells expressing the receptor tyrosine kinase Axl. J Biol Chem 272: 23285-23291, 1997.

11. Nakano T, Higashino K, Kikuchi N, et al: Vascular smooth muscle cell-derived, Gla-containing growth-potentiating factor for $\mathrm{Ca}(2+)$-mobilizing growth factors. J Biol Chem 270: $5702-5705,1995$.

12. Melaragno MG, Wuthrich DA, Poppa V, et al: Increased expression of Axl tyrosine kinase after vascular injury and regulation by $\mathrm{G}$ protein-coupled receptor agonists in rats. Circ Res 83: 697-704, 1998.

13. O'Donnell K, Harkes IC, Dougherty L and Wicks IP: Expression of receptor tyrosine kinase Axl and its ligand Gas6 in rheumatoid arthritis: evidence for a novel endothelial cell survival pathway. Am J Pathol 154: 1171-1180, 1999.

14. Hasanbasic I, Cuerquis J, Varnum B and Blostein MD: Intracellular signaling pathways involved in Gas6-Axl-mediated survival of endothelial cells. Am J Physiol Heart Circ Physiol 287: H1207-H1213, 2004.

15. D'Arcangelo D, Gaetano C and Capogrossi MC: Acidification prevents endothelial cell apoptosis by Axl activation. Circ Res 91: e4-e12, 2002.

16. Hasanbasic I, Rajotte I and Blostein $M$ : The role of gamma-carboxylation in the anti-apoptotic function of gas6. J Thromb Haemost 3: 2790-2797, 2005.

17. Ruan GXand Kazlauskas A: Axl isessential forVEGF-A-dependent activation of PI3K/Akt. Embo J 31: 1692-1703, 2012.

18. Alciato F, Sainaghi PP, Sola D, Castello L and Avanzi GC: TNF-alpha, IL-6, and IL-1 expression is inhibited by GAS6 in monocytes/macrophages. J Leukoc Biol 87: 869-875, 2010.

19. Ganopolsky JG, Abid MR, Aird WC and Blostein MD: GAS6-induced signaling in human endothelial cells is mediated by FOXO1a. J Thromb Haemost 6: 1804-1811, 2008.

20. Kawasaki K, Watabe T, Sase H, et al: Ras signaling directs endothelial specification of VEGFR2(+) vascular progenitor cells. J Cell Biol 181: 131-141, 2008.

21. Xu J, Liu X, Jiang Y, et al: MAPK/ERK signalling mediates VEGF-induced bone marrow stem cell differentiation into endothelial cell. J Cell Mol Med 12: 2395-2406, 2008.

22. Yan X,CaiS,Xiong X, et al: Chemokine receptor CXCR7 mediates human endothelial progenitor cells survival, angiogenesis, but not proliferation. J Cell Biochem 113: 1437-1446, 2012.

23. Wang F, Wang Y, Zhang L and Zou L: Gene modification with integrin-linked kinase improves function of endothelial progenitor cells in pre-eclampsia in vitro. J Cell Biochem 112: 3103-3111, 2011.

24. Kalka C, Masuda H, Takahashi T, et al: Transplantation of ex vivo expanded endothelial progenitor cells for therapeutic neovascularization. Proc Natl Acad Sci USA 97: 3422-3427, 2000. 
25. Kawamoto A, Tkebuchava T, Yamaguchi J, et al: Intramyocardial transplantation of autologous endothelial progenitor cells for therapeutic neovascularization of myocardial ischemia. Circulation 107: 461-468, 2003.

26. Nakano T, Kawamoto K, Kishino J, Nomura K, Higashino K and Arita $\mathrm{H}$ : Requirement of gamma-carboxyglutamic acid residues for the biological activity of Gas6: contribution of endogenous Gas6 to the proliferation of vascular smooth muscle cells Biochem J 323: 387-392, 1997.

27. Yanagita M, Arai H, Nakano T, et al: Gas6 induces mesangial cell proliferation via latent transcription factor STAT3. J Biol Chem 276: 42364-42369, 2001.

28. Bellosta P, Zhang Q, Goff SP and Basilico C: Signaling through the ARK tyrosine kinase receptor protects from apoptosis in the absence of growth stimulation. Oncogene 15: 2387-2397, 1997.

29. Goruppi S, Ruaro E, Varnum B and Schneider C: Gas6-mediated survival in NIH3T3 cells activates stress signalling cascade and is independent of Ras. Oncogene 18: 4224-4236, 1999.

30. Allen MP, Linseman DA, Udo H, et al: Novel mechanism for gonadotropin-releasing hormone neuronal migration involving Gas6/Ark signaling to p38 mitogen-activated protein kinase. Mol Cell Biol 22: 599-613, 2002.

31. Fridell YW, Villa JJ, Attar EC and Liu ET: GAS6 induces Axl-mediated chemotaxis of vascular smooth muscle cells. J Biol Chem 273: 7123-7126, 1998.

32. Angelillo-Scherrer A, de Frutos P, Aparicio C, et al: Deficiency or inhibition of Gas6 causes platelet dysfunction and protects mice against thrombosis. Nat Med 7: 215-221, 2001.

33. Jiang L, Liu CY, Yang QF, Wang P and Zhang W: Plasma level of growth arrest-specific 6 (GAS6) protein and genetic variations in the GAS6 gene in patients with acute coronary syndrome. Am J Clin Pathol 131: 738-743, 2009.

34. Holland SJ, Powell MJ, Franci C, et al: Multiple roles for the receptor tyrosine kinase axl in tumor formation. Cancer Res 65 : 9294-9303, 2005.
35. Gallicchio M, Mitola S, Valdembri D, et al: Inhibition of vascular endothelial growth factor receptor 2-mediated endothelial cell activation by Axl tyrosine kinase receptor. Blood 105: 1970-1976, 2005.

36. Li Y, Ye X, Tan C, et al: Axl as a potential therapeutic target in cancer: role of Axl in tumor growth, metastasis and angiogenesis. Oncogene 28: 3442-3455, 2009.

37. Ruan GX and Kazlauskas A: Lactate engages receptor tyrosine kinases axl, tie2, and vascular endothelial growth factor receptor 2 to activate phosphoinositide 3-kinase/akt and promote angiogenesis. J Biol Chem 288: 21161-21172, 2013.

38. Allen MP, Zeng C, Schneider K, et al: Growth arrest-specific gene 6 (Gas6)/adhesion related kinase (Ark) signaling promotes gonadotropin-releasing hormone neuronal survival via extracellular signal-regulated kinase (ERK) and Akt. Mol Endocrinol 13: 191-201, 1999.

39. Shankar SL, O'Guin K, Cammer M, et al: The growth arrest-specific gene product Gas6 promotes the survival of human oligodendrocytes via a phosphatidylinositol 3-kinase-dependent pathway. J Neurosci 23: 4208-4218, 2003.

40. Wang JY, Lee YT, Chang PF and Chau LY: Hemin promotes proliferation and differentiation of endothelial progenitor cells via activation of AKT and ERK. J Cell Physiol 219: 617-625, 2009.

41. Munoz-Chapuli R, Quesada AR and Angel MM: Angiogenesis and signal transduction in endothelial cells. Cell Mol Life Sci 61: 2224-2243, 2004.

42. Park IK, Giovenzana C, Hughes TL, Yu J, Trotta R and Caligiuri MA: The Axl/Gas6 pathway is required for optimal cytokine signaling during human natural killer cell development. Blood 113: 2470-2477, 2009.

43. Angelillo-Scherrer A, Burnier L, Lambrechts D, et al: Role of Gas6 in erythropoiesis and anemia in mice. J Clin Invest 118: 583-596, 2008

44. Chao H and Hirschi KK: Hemato-vascular origins of endothelial progenitor cells? Microvasc Res 79: 169-173, 2010. 